\title{
THE OPTIMIZATION OF FLOW RATES OF AN EXTRUDER
}

\author{
I.O. Popoola ${ }^{1}$ and S.A. Oke ${ }^{2}$ \\ Department of Mechanical Engineering \\ University of Lagos, Nigeria \\ 1.
}

\begin{abstract}
The article addresses how the flow rates of an extruder can be optimized. It mentions the plastic recycling industry as an example, which is only one of many solid waste recycling industries. The literature on flow rates is reviewed to demonstrate a gap that the current study aims to fills, in the hope that it will stimulate further research in a fertile area.

\section{OPSOMMING}

Die artikel adresseer die vraagstuk van vloeitempo van 'n ekstrusieproses. Dit handel met ' $\mathrm{n}$ voorbeeld van 'n plastiekherwinningsproses wat spruit uit soliede afvalverwerking. " $n$ Literatuurstudie toon hoedat die navorsing verdere areas wat braak lê, aanspreek in die hoop dat verdere studie gestimuleer sal word.
\end{abstract}




\section{INTRODUCTION}

There is a growing concern among governments, consumers, and various stakeholders in the environment about the enormous amount of waste generated from materials either during the manufacturing process or at the disposal stage of finished goods [23]. Consequently, serious efforts are made by interest groups to refocus the attention of manufacturers on an improved manufacturing culture, dubbed "environmentally-conscious manufacturing" $[21,26]$.

One of the measures adopted by governments is to ensure the compliance of manufacturing organizations by requiring statutory "environmental impact assessment" reports. Governments increasingly publicize the negative effects that environmentally unfriendly products have on current and future generations. To this end, they encourage recycling and recycling practices $[8,9]$. For example, a strong indication of the "end-of-life directive" endorsed by the member states of the European Union is that, if resources are not recycled, a time may come when very limited resources remain available for human use [16], and we suffer from shortages of these important resources.

Recycling industries face serious economic problems that increase the cost of recycling [1, 14, 18, 25]. In resolving this problem, a number of management strategies are adopted over time. Such strategies may include business process reengineering, downsizing, system restructuring, lean manufacturing, etc. All these strategies are aimed at optimizing the system variables through minimizing costs and maximizing profits. The extruder in a recycling plant is one of the most important components of the system that dictates the unit cost of production and thus the profit made by the system [27]. Adequate design and control of flow rates is obviously necessary in order to optimize the recycled product $[3-5,11,13]$. To the authors' knowledge, no documentation exists in this respect. This paper is therefore an attempt to model the flow rates of an extrusion process with particular reference to the plastic recycling industry.

\section{RELATED LITERATURE}

This section reviews the literature relevant to the subject surveyed here. In particular, studies that focus on extrusion are examined.

Kochhar and Parnaby [15] examine alternative methods for determining plastics extrusion process models, suitable for high level control. The authors demonstrate the importance of time-series techniques for feed forward control, and describe the results of an extrusion process experiment carried out on a single extruder used for processing polyethylene. Some results of exploratory control strategy simulations are included. Control of plastic pressure and temperature at the die is suggested as an effective indirect means of controlling die flow rate in most industrial situations.

In another study, the screening of variables for extrusion of rice flour employing a Placket-Burman design was carried out by Guha et al [12]. The variables include hardware variables (mixing disk and reverse pitch sinew elements), feed variables 
(moisture, sugar, salt and amylase contents, and particle size) and operating variables (barrel temperature, feed rate, and screw speed). The response functions were extrusion characteristics (torque, specific mechanical energy, and residence time), product attributes (water solubility index, water absorption index, and bulk density, peak viscosity, hot paste viscosity, and cold paste viscosity). The response functions were greatly affected by the hardware variables. A Plackett-Burman experimental design can serve as a useful tool for screening large numbers of variables and reducing the number of experiments.

In a noteworthy study, Govindasamy et al [7] investigated the single screw extruder as a bioreactor for sago starch hydrolysis. In particular, simultaneous pregelatinization and preliquefaction of sago starch with a thermostable amylase was carried out in a Brabender single screw extruder. Response surface methodology was employed to study the effects of processing conditions; feed moisture contact (21 - 38\%), enzyme concentrations $(1.48-6.52 \%)$ and mass temperatures in the compression and die zones $\left(70.5-97.5^{\circ} \mathrm{C}\right)$, on the properties of the extrudates. Twenty runs were carried out, based on a multifactorial composite rotatable design. Changes in the dextrose equivalent (DE), water solubility index (WSI), water absorption index (WAI), degree of gelatinization (DG), and high performance size exclusion chromatography (HPSEC) profiles were assessed. From the HPSEC profiles, the degree of degradation (DGR) and oligosaccharide content was calculated. Feed moisture content and enzyme concentration were found to be the most significant variables, affecting most of the measured physico-chemical properties. Hydrolysis of starch granules was the fundamental reaction that occurred during the extrusion process, as indicated by the higher DE, WSI, and oligosaccharide content; and correspondingly lower WAI, DG, and DGR. Product spectra from HPSEC showed that the amylopectin (AP) was preferentially degraded and amylose (AM) was apparently protected. The predominant oligosaccharide species were G3, G5, and G6.

Murdoch [20] studies the tritium inventory issues for future reactors: choicers, parameters, limits. The author determines the tritium inventory of an experimental fusion reactor or power plant for a broad range of factors, including plasma physics parameters, machine operating scenarios, the design of material selections for components (principally plasma facing components (PFCs) and elements of the fuel cycle), and system integration choices. The influences that these factors exert on tritium inventory, and the options available to designers to minimize tritium inventories in the plant as a whole - especially in vulnerable systems - are discussed in the paper. For power reactors, the potential trade-off between plant availability and the minimization of tritium inventory will be more critical than in experimental machines. The requirement to meet overall site release limits dictates that tritium inventories of larger machines now in detailed design (ITER) and conceptual (DEMO) phases cannot be permitted to scale linearly as a function of time-averaged fusion power from present generation machines. This necessitates the development of robust low-inventory processes, a concentrated effort on inventory segregation, the capability to follow inventory transfers between systems, and implementation of defensive in-depth measures such as multiple containments and engineered safety barriers throughout the plant. The progress which has been made on these topics in 
the last few years is reviewed, and areas where additional work is necessary are identified.

In their study, Garbriele et al [6] studied the optimal design of a single-screw extruder for liquorice candy production using a rheology based approach. The aim of this work was to investigate the rheological behaviour of liquorice extract, in order properly to design and optimize a single-screw extruder dedicated to liquorice production. A stress-shear rate law was determined and a simplified analysis of the extruder performance was carried out. The velocity profiles on the extruder channel were determined by using a numerical method, while a few geometrical parameters, like the channel depth and the helix angle, were optimized to obtain the maximum flow rate as a function of different operating conditions. A power law relationship between either the flow rate or the power consumption and the screw speed was established. The deviation from linearity was expressed by an exponent that in all the cases examined was found to be almost constant, and ranged from 1.22 to 1.30.

Martin et al [19] studied the rheological behaviour of an industrial talc-based paste featuring a solids volume fraction of 0.49 , in a viscous aqueous surfactant solution using a form of capillary rheometry. Standard approaches for determining wall slip velocities yielded non-physical results, although the data could be correlated using the Jastrzebski wall slip condition. The material was also characterized using the Benbow-Bridgwater approach, and showed variations with in-die land diameter, which could not be correlated using simple corrections. The parameters obtained featured an accuracy of $\pm 20 \%$. Density measurements indicated that dilation and liquid-phase migration were important features of the flow, and that the stresses are chiefly borne by the liquid-phase. The flow behaviour is interpreted in terms of the component properties: the difficulty in rheological characterization is attributed to shear-induced re-orientation of the talc platelets during flow.

In a study by Cronin et al [2], the effect of non-uniformity in the weights of an extruded food product on the efficiency of the subsequent packaging operation is analyzed. The focus is on reducing the overweight of the packs by better control over dispersion on product weight. Samples from industrially extruded food products are analyzed for variation in dimensional parameters and density. Variability in the product width dimension is shown to be the most significant source of weight variability. The control required over product width in order to obtain acceptable levels of pack overweight is quantified. It is not practically possible to eliminate product weight variability. Hence, alternative packing strategies that may be more successful in reducing the amount of product over-weight are examined.

Gontz et al [10] study the possible optimization of pastes and the relevant apparatus in process engineering by MRI flow experiments. In their paper, the spatially resolved determination of velocities in suspension by means of nuclear magnetic resonance (NMR) imaging (MRI) techniques is described and applied to steady tube flows (with regard to the total flow rate) in different geometries. Three types of suspension with different solid volume concentrations are examined to demonstrate the influence of the observed flow pattern. MRI makes it possible to study the flow of multiphase materials with various forms of contrast (e.g. spin density, relaxation 
and spectroscopic data, diffusive and convective transport) spatially resolved. Thus, even optically opaque suspensions can be studied in the interior of the material and the device. In this work the local probability distribution of single velocity components is determined. From this probability distribution, both the local mean value and the standard deviation can be derived. The standard deviation can be interpreted as the local dispersion coefficient of the velocity component.

We have reviewed wide-ranging studies on the extrusion process, with appreciable efforts made by previous scholars. Unfortunately, none of the studies captured in this literature review treated the particular subject of optimizing the plastic recycling extrusion process. This is a serious gap that the current study addresses.

\section{MODELLING FRAMEWORK}

In modelling the flow rates of an extruder $(Q)$, a number of variables must be considered. In particular, eight variables are considered: $Q=f\left(D, h, w, N, L, \mu_{a}, P\right.$, $\theta)$. The variables are defined as follows:

$\begin{array}{lll}Q & = & \text { flow rates of the extruder } \\ w & = & \text { channel width } \\ h & = & \text { channel depth } \\ D & = & \text { screw diameter } \\ \theta & = & \text { helix angle } \\ N & = & \text { screw speed } \\ L & = & \text { metering zone length } \\ \mu_{a} & = & \text { apparent viscosity } \\ P & = & \text { pressure }\end{array}$

In a previous work, the authors developed a framework for the plastic recycling paradigm based on a mathematical relationship between flow rate and the quantity of recycled material in a plastic recycling process [23]. The focus is on the extrusion process of the recycling system. The results indicate the dynamics of the system. The model discussed in this work is built on the framework proposed by the authors [23]. The model is defined as follows:

$\mathrm{Q}=\frac{\pi \mathrm{Dhw} \operatorname{Cos}^{2} \theta}{2} \mathrm{~N}-\frac{\mathrm{h}^{3} \mathrm{w} \operatorname{Cos} \theta}{12 \mathrm{~L}} \frac{P}{\mu_{a}}=\mathrm{A} \cdot \mathrm{N}-\mathrm{B} \cdot \frac{P}{\mu_{a}}$

From the basic techniques of maximum and minimum values in calculus, there are two types of function that could be considered. One is when $Q$ is only dependent on a single parameter - say, A (i.e. $Q f(A)$ ). The other is when $Q$ is dependent on two parameters - say, A and B (i.e. $Q=f(A, B)$ ).

In this case, for effectiveness, it is more accurate to apply the second type of function, where $Q$ is dependent on two parameters. The choice of these parameters depends on which ones the model depends upon most. However, from the alreadycited paper by the authors [23], the two top parameters are channel depth $(h)$ and 
channel width $(w)$. These two were tested for points of turning, but the results were only mathematically reasonable, not practicable in the industry. For this reason, it was considered better to reduce this to a single variable function.

From the sensitivity analysis, it was established that the parameter that the model is most sensitive to is the channel depth, $h$. It was also observed that the gradient of the channel depth, $h$, either when increased or reduced, was much more than that of the next parameter - channel width, $w$. For this reason, it can be assumed that $Q$ is only dependent on the variable $h$. Therefore, $Q$ is a function of $h($ i.e. $Q=f(h)$ ).

Consider a function of the form $Q=f(h)$.

Since $\mathrm{Q}=\frac{\pi \mathrm{DhwNC} \operatorname{Cos}^{2} \theta}{2}-\frac{\mathrm{h}^{3} \mathrm{wPCos} \theta}{12 \mathrm{~L} \mu_{a}}$

$\frac{\mathrm{dQ}}{\mathrm{dh}}=\frac{\pi \mathrm{DwNC} \cos ^{2} \theta}{2}-\frac{\mathrm{wPCos} \theta}{4 \mathrm{~L} \mu_{a}} \mathrm{~h}^{2}$

To determine the turning point $\left(\mathrm{Q}_{\mathrm{o}}, \mathrm{h}_{\mathrm{o}}\right), \frac{\mathrm{dQ}}{\mathrm{dh}}=0$, it means that

$\frac{\pi \mathrm{DwNC} \cos ^{2} \theta}{2}-\frac{\mathrm{wPCos} \theta}{4 \mathrm{~L} \mu_{a}} \mathrm{~h}^{2}=0$. From here, we obtain

$\frac{\mathrm{wPCos} \theta}{4 \mathrm{~L} \mu_{a}} \mathrm{~h}^{2}=\frac{\pi \mathrm{DwN} \operatorname{Cos}^{2} \theta}{2}$, that gives the formula

$\mathrm{h}^{2}=\frac{\pi \mathrm{DwNCos} \cos ^{2} \theta}{2} \times \frac{4 \mathrm{~L} \mu_{a}}{{ }_{\mathrm{wPC}} \operatorname{Cos} \theta}=$

$\frac{2 \pi \mathrm{DNL} \mu_{a} \operatorname{Cos} \theta}{\mathrm{P}}$

It follows that

$\mathrm{h}= \pm\left[\frac{2 \pi \mathrm{DNL} \mu_{a} \operatorname{Cos} \theta}{\mathrm{P}}\right]^{\frac{1}{2}}$

In engineering practice, the negative part is neglected since it is not practicable.

$\therefore \mathrm{h}_{\mathrm{o}}=\left[\frac{2 \pi \mathrm{DNL} \mu_{a} \operatorname{Cos} \theta}{\mathrm{P}}\right]^{\frac{1}{2}}$ 
In order to determine the value of $Q_{o}$ at this point, the value of $h$ would be substituted into $Q=f(h)$.

This gives

$$
\begin{aligned}
& \mathrm{Q}=\frac{\pi \mathrm{DwN} \operatorname{Cos}^{2} \theta}{2} \mathrm{~h}-\frac{\mathrm{wPCos} \theta}{12 \mathrm{~L} \mu_{a}} \mathrm{~h}^{3} \\
& =\frac{\pi \mathrm{DwNCos}{ }^{2} \theta}{2}\left[\frac{2 \pi \mathrm{DNL} \mu_{a} \operatorname{Cos} \theta}{\mathrm{P}}\right]^{\frac{1}{2}}-\frac{\mathrm{wPCos} \theta}{12 \mathrm{~L} \mu_{a}}\left[\frac{2 \pi \mathrm{DNL} \mu_{a} \operatorname{Cos} \theta}{\mathrm{P}}\right]^{\frac{3}{2}} \\
& =\frac{1.414}{2} \mathrm{w}(\pi \mathrm{DN})^{\frac{3}{2}}\left(\frac{\mathrm{L} \mu_{a}}{\mathrm{P}}\right)^{\frac{1}{2}}(\operatorname{Cos} \theta)^{\frac{5}{2}}-\frac{2.83}{12} \mathrm{w}(\pi \mathrm{DN})^{\frac{3}{2}}\left(\frac{\mathrm{L} \mu_{a}}{\mathrm{P}}\right)^{\frac{1}{2}}(\operatorname{Cos} \theta)^{\frac{5}{2}} \\
& =0.707 \mathrm{w}(\pi \mathrm{DN})^{\frac{3}{2}}\left(\frac{\mathrm{L} \mu_{a}}{\mathrm{P}}\right)^{\frac{1}{2}}(\operatorname{Cos} \theta)^{\frac{5}{2}}-0.236 \mathrm{w}(\pi \mathrm{DN})^{\frac{3}{2}}\left(\frac{\mathrm{L} \mu_{a}}{\mathrm{P}}\right)^{\frac{1}{2}}(\operatorname{Cos} \theta)^{\frac{5}{2}}
\end{aligned}
$$

Factorizing common terms:

$$
\begin{aligned}
& \mathrm{Q}_{\mathrm{o}}=(0.707-0.236)(\mathrm{w})(\pi \mathrm{DN})^{\frac{3}{2}}\left(\frac{\mathrm{L} \mu_{a}}{\mathrm{P}}\right)^{\frac{1}{2}}(\mathrm{Cos} \theta)^{\frac{5}{2}}= \\
& 0.471 \mathrm{w}(\pi \mathrm{DN})^{\frac{3}{2}}\left(\frac{\mathrm{L} \mu_{a}}{\mathrm{P}}\right)^{\frac{1}{2}}(\operatorname{Cos} \theta)^{\frac{5}{2}}
\end{aligned}
$$

Therefore the turning point occurs at the point:

$$
\left[(0.47) \operatorname{lw}(\pi \mathrm{DN})^{\frac{3}{2}}\left(\frac{\mathrm{L} \mu_{a}}{\mathrm{P}}\right)^{\frac{1}{2}}(\operatorname{Cos} \theta)^{\frac{5}{2}}\right],\left[\left(\frac{2 \pi \mathrm{DNL} \mu_{a} \operatorname{Cos} \theta}{\mathrm{P}}\right)^{\frac{1}{2}}\right]
$$

To test the type of turning point:

$$
\begin{aligned}
& \left.\frac{\mathrm{d}^{2} \mathrm{Q}}{\mathrm{dh}^{2}}\right|_{\mathrm{h}=\mathrm{h}_{\odot}}=-\frac{2 \mathrm{wPCos} \theta}{4 \mathrm{~L} \mu_{a}} \mathrm{~h}_{\mathrm{o}}=-\frac{\mathrm{wPCos} \theta}{2 \mathrm{~L} \mu_{a}} \mathrm{~h}_{\mathrm{o}}= \\
& -\frac{\mathrm{wPCos} \theta}{2 \mathrm{~L} \mu_{a}} \mathrm{~h}_{\mathrm{o}}\left[\frac{2 \pi \mathrm{DNL} \mu_{a} \operatorname{Cos} \theta}{\mathrm{P}}\right]^{\frac{1}{2}}
\end{aligned}
$$


$=-\frac{1.414}{2} \mathrm{~W}(\pi \mathrm{DN})^{\frac{1}{2}}\left(\frac{\mathrm{L} \mu_{a}}{\mathrm{P}}\right)^{-\frac{1}{2}}(\operatorname{Cos} \theta)^{\frac{3}{2}}=-0.707 \mathrm{w}(\pi \mathrm{DN})^{\frac{1}{2}}\left(\frac{\mathrm{L} \mu_{a}}{\mathrm{P}}\right)^{-\frac{1}{2}}(\operatorname{Cos} \theta)^{\frac{3}{2}}$

Since all the parameters are positive, the second derivative, $\frac{\mathrm{d}^{2} \mathrm{Q}}{\mathrm{dh}^{2}}$, is negative. This implies that the point is a maximum.

\subsection{Verification with assumed realistic data}

The data are as follows:

Screw diameter, $\mathrm{D}=0.06 \mathrm{~m}$

Screw speed, $\mathrm{N}=1.67 \mathrm{rps}$

Apparent viscosity, $\mu_{a}=1750 \mathrm{~Pa} . \mathrm{S}$
Channel width, $\mathrm{w}=0.05 \mathrm{~m}$

Metering zone length, $\mathrm{L}=1.25 \mathrm{~m}$

Helix angle, $\theta=\pi / 4$ radians

At the turning point:

$\mathrm{h}_{\mathrm{o}}=\left[\frac{2 \pi \mathrm{DNL} \mu_{a} \operatorname{Cos} \theta}{\mathrm{P}}\right]^{\frac{1}{2}}=\left[\frac{2 \pi \times 0.06 \times 1.67 \times 1.25 \times 1750 \times \operatorname{Cos} \pi / 4}{50 \times 10^{6}}\right]^{\frac{1}{2}}$

$=4.413 \times 10^{-3} \mathrm{~m}$

$\mathrm{Q}_{\mathrm{o}}=(0.471) \mathrm{W}(\pi \mathrm{DN})^{\frac{3}{2}}\left(\frac{\mathrm{L} \mu_{a}}{\mathrm{P}}\right)^{\frac{1}{2}}(\mathrm{Cos} \theta)^{\frac{5}{2}}$

$=(0.471)(0.05)(\pi \times 0.06 \times 1.67)^{\frac{3}{2}}\left(\frac{1.25 \times 1750}{50 \times 10^{6}}\right)^{\frac{1}{2}}(\operatorname{Cos} \pi / 4)^{\frac{5}{2}}=1.157 \times 10^{-5} \mathrm{~m}^{3} / \mathrm{s}$

$\therefore$ The turning point is at $\left(1.157 \times 10^{-5}, 4.413 \times 10^{-3}\right)$ which is a maximum point.

\subsection{Effect of optimization on model performance}

The effect of optimizing the model can best be evaluated by considering the difference between the original value of the flow rate and the optimized value. To achieve the purpose of generalization in order to be applicable to any situation in practice, it is best evaluated as a percentage.

First, considering the percentage change in flow rate, $Q$, which is being optimized:

$\% \Delta$ in $\mathrm{Q}=\frac{\mathrm{Q}_{\mathrm{o}}-\mathrm{Q}}{\mathrm{Q}}$

where: 
$\mathrm{Q}_{\mathrm{o}}=$ flow rate value after optimization $=3.415 \times 10^{-4} \mathrm{~m}^{3} / \mathrm{s}$

$\mathrm{Q}=$ flow rate value before optimization $=9.986 \times 10^{-6} \mathrm{~m}^{3} / \mathrm{s}$

$\% \Delta$ in $\mathrm{Q}=\frac{1.157 \times 10^{-5}-9.986 \times 10^{-6}}{9.986 \times 10^{-6}} \times 100 \%=15.86 \%$

Secondly, considering the percentage change in channel depth $h$, used to attain optimization:

$\% \Delta$ in $\mathrm{h}=\frac{\mathrm{h}_{\mathrm{o}}-\mathrm{h}}{\mathrm{h}}$

where, $\mathrm{h}_{\mathrm{o}}=$ channel depth value after optimization $=4.413 \times 10^{-3} \mathrm{~m}$

$\mathrm{h}=$ channel depth value before optimization $=3 \times 10^{-3} \mathrm{~m}$

$\% \Delta$ in $\mathrm{Q}=\frac{4.413 \times 10^{-3}-3 \times 10^{-3}}{3 \times 10^{-3}}=47.1 \%$

\section{IMPLICATIONS FOR DECISION MAKING}

In any recycling process that involves the use of an extruder, a flow rate, $Q$, is usually expected from the machine. From this optimization analysis, it has been discovered that the flow rate, $Q$, can be increased by $15.87 \%$ only by increasing the channel depth, $h$, by $47.1 \%$. This increase in flow rate will increase the quantity of the recycled products that will invariably increase the profit of the company within a specified period. In addition, if a deadline is given to produce a certain quantity of recycled product, this will assist the company to meet the deadline.

The cost of achieving an optimized flow rate has also been greatly reduced. This is best discussed in considering the number of actual parameters involved within the machine. If all eight parameters were to be adjusted to attain optimization, the cost would be excessive. If a single parameter is changed to achieve the same result in optimization, then the cost involved is greatly reduced.

The optimized model has been developed to become a function dependent on seven parameters, as against the original model which was dependent on eight parameters. The eighth parameter - channel depth, $h$ - was used for optimization, and it no longer appears as a parameter. It should be noted that this is only applicable in situations where the channel depth has been increased by $47.1 \%$ for the purpose of optimizing the model.

\section{SENSITIVITY ANALYSIS OF OPTIMIZED MODEL}

The optimized model obtained after maximizing the original model is: 
$\mathrm{Q}_{\mathrm{o}}=0.471 \mathrm{w}(\pi \mathrm{DN})^{\frac{3}{2}}\left(\frac{\mathrm{L} \mu_{a}}{\mathrm{P}}\right)^{\frac{1}{2}}(\operatorname{Cos} \theta)^{\frac{5}{2}}$

This model is applicable only to extruder processes. Extensive work needs to be done by future investigators to determine its applicability to recycling systems in general. For the purpose of comparing the optimized model with the original model from Popoola and Oke [23], sensitivity analysis is carried out on the optimized model [22, 24]. These computations are shown in the Appendix for each varying parameter. The evaluated gradients at 50\% reduction and 150\% increment are therefore tabulated below.

\begin{tabular}{|c|c|c|}
\hline & \multicolumn{2}{|c|}{ Gadients $\left(\mathrm{x} \mathrm{10} 0^{-4}\right)$} \\
\hline D & Reducing by $50 \%$ & Increasing by $150 \%$ \\
\hline w & 2.046 & 4.574 \\
L & 2.313 & 2.313 \\
\hline N & 0.06543 & 0.02926 \\
\hline$\mu a$ & 0.07352 & 0.1644 \\
P & $4.675 \times 10-5$ & 2.091 \\
$\theta$ & $3.272 \times 10^{-10}$ & $2.927 \times 10^{-11}$ \\
& -0.2337 & -0.1504 \\
\hline
\end{tabular}

From the tabulated results, it can be seen that the same order of sensitivity of the model to the parameters is observed, even when the parameters are reduced.

This order is shown below.

Channel width, $w$

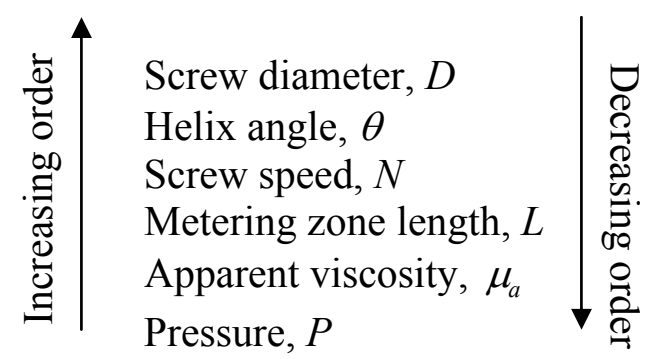

Conversely, the order of sensitivity changes randomly if the parameters are increased. 
This order is shown below:

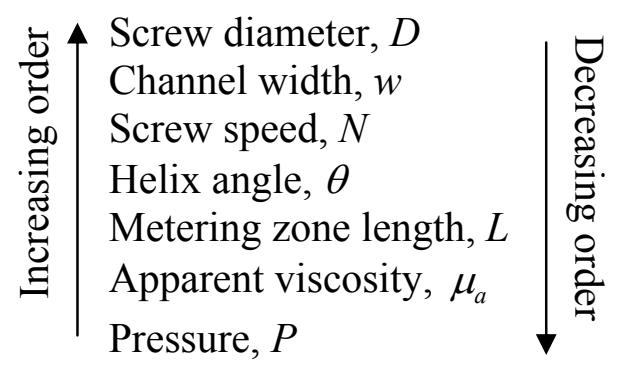

The only parameters that follow the same order are the last three parameters: metering zone length, $L$; apparent viscosity, $\mu_{a}$; pressure, $P$.

It is also noticeable from the patterns of the various graphs that the four parameters screw diameter, $D$; channel width, $w$; screw speed, $N$; and Pressure, $P$, which in the original model were of similar patterns (linear graph) - no longer follow the same pattern. Only the channel width, $w$, remains a linear graph.

In the optimized model, the screw diameter, $D$ and screw speed, $N$ reflect the same pattern. Metering zone length, $L$, apparent viscosity, $\mu_{a}$, and pressure, $P$ also reflects the same pattern. The helix angle $\theta$ reflects a different pattern from other parameters.

\section{DISCUSSION OF RESULTS}

For every developed mathematical model, the determination of maximum and minimum values has been found very useful. In the work, the same principles have been applied, and good results have been obtained. The developed model was extended to the maximization of the flow rate. This is the aim of every producer: to be able to achieve maximum production with the available input materials. In the process of optimization, it was thought that if the two parameters that the models are most sensitive to were examined closely, the results obtained might not be applicable in the industry. For these reasons, only the parameters that are most sensitive to channel depth were finally considered.

After the optimization, it was observed that the parameter was no longer present in it. This implied that the optimized model is no longer dependant on the value of the channel depth.

\section{CONCLUSIONS}

Economics tell us that resources are scarce. It is therefore not advisable to keep the model just the way it has been developed without any further consideration or extension. This warranted the extended maximization of the model. This aspect of the work investigates the possible value of the parameter to which the model is most sensitive, which will result in the maximum possible flow rate without necessarily changing the input or materials. 
The contribution of this work is therefore measured by its ability to produce the maximum flow rate from the same input materials. The model developed is suited to the recycling industry - in particular, the plastic recycling system. It produces a maximum flow rate from the same input material. As a result, the process saves a lot of time and simultaneously meets the demands of the customer. The application of the optimized model assures that the recycler is being used to obtain the maximum production possible. It increases the production and, in the long run, favours the recycler in two significant ways: (i) maximizing profit, and (ii) retaining customers' goodwill.

\section{REFERENCES}

[1] Curlee T.R., and Das S., 1998. "The viability of recycling plastic by tertiary processes", Journal of Solid Waste Technology and Management, Vol. 25, No. 3\&4. muse.wider.edu/ $\sim$ sxw0004/cumindex.html

[2] Cronin, K., Fitzpatrick, J., McCarthy, C., 2003. "Packaging strategies to counteract weight variability in extruded food products", Journal of Food Engineering, vol. 56, issue 4, pp. 353-360.

[3] Feiock, R.C. and Kalan, L.G, 1999. "Assessing the performance of solid waste recycling programs over time", American Review of Public Administration, Vol. 31, No. 1, pp. 22-32.

[4] Fullerton, D. and Kinnaman, T.C., 1995. "Garbage, recycling and illicit burning or dumping", Journal of Environmental Economics and Management, 29, pp. 78-91.

[5] Fullerton, D. and Kinnaman, T.C., 2000. "Garbage and recycling with endogenous local policy", Journal of Urban Economics, vol. 48, pp. 419-442. muse.wider.edu/ sxw0004/cumindex.html

[6] Garbriele, D., Curcio, S., Cindio, B., 2001. "Optimal design of single-screw extruder for liquorice candy production: a rheology based approach", Journal of Food Engineering, vol. 48, issue 1, pp. 33-44.

[7] Gouindasamy, S., Campanella, O.H., Oates, C.G., 1997. "The single screw extruder as a biorector for sago starch hydrolysis", Food Chemistry, vol. 60, Issue 1 , pp. 1-11.

[8] Goulias D.G., 2001. "Durability evaluation of asphalt mixtures modified with recycled tire rubber", Journal of Solid Waste Technology and Management, vol. 27, No. 3\&4. muse.wider.edu/ sxw0004/cumindex.html

[9] Goulias D.G., 2001. "Reinforced recycled polymer based composites for highway poles", Journal of Solid Waste Technology and Management, vol 27, No 2. muse.wider.edu/ $\sim$ sxw0004/cumindex.html

[10] Gontz, J., Zick, K., Kreibich, W., 2003. "Possible optimization of pastes and the according apparatus in process engineering by MRI flow experiments", Chemical Engineering and Processing, vol. 42, issue 7, pp. 517-534.

[11] Grote, H.; Freise, A.; Malec, M.; Heinzel, G.; Willke, B.; Luck, H.; Strain, K.A.; Hough, J. and Danzmann, K., 2004. "Dual Recycling for GEO 600" Classical and Quantum Gravity, vol. 21, No. 5, pp. S473-S480.

[12] Guha, M., Ali, S.Z., Bhattacharya, S., 2003. "Screening of variables for extrusion of rice flour employing a placket-Burman design", Journal of Food Engineering, vol. 57, issue 2, pp. 135-144. 
[13] Heinzel, G.; Freise, A.; Grote, H.; Strain, K. and Danzamann, K., 2002. "Dual recycling for GEO 600", Classical and Quantum Gravity, vol. 19, No. 7, pp. 1547-1553.

[14] Kimbrough D.E., Wong P.W., Biscoe J., Kim J., 1996. "A critical review of photographic and radiographic silver recycling", Journal of Solid Waste Technology and Management, vol. 23 No. 4. muse.wider.edu/ sxw0004/ cumindex.html

[15] Kochhar, A.K., Parnaby, J., 1977. "Dynamical modeling and control of plastics extrusion processes", Automatica, vol. 13, issue 2, pp. 177-183.

[16] Kumaran, D.S., Ong. S.K., Tan, R.B.H. and Nee, A.Y.C., 2001. "Environmental lifecycle cost analysis of products", Environmental Management and Health, vol. 12, No. 3, pp. 260-276.

[17] Levis, S.R., Deasy, P.B., 2001. "Pharmaceutical application of size reduced grades of surfactant co-processed microcrystalline cellulose", International Journal of Pharmaceutics, vol. 230, issues 1-2, pp. 25-33.

[18] Malec, M.;Grote, H.; Freise, A.; Heinzel, G.; Strain, K.A.; Hough, J. and Danzmann, K., 2004. "Towards dual recycling with the aid of time and frequency domain simulations", Classical and Quantum Gravity, vol. 21, No. 5, pp. S991-S998.

[19] Martin, P.J., Wilson, D.I., Bonnett, P.E., 2004. "Rheological study of a talcbased paste for extrusion granulation", Journal of the European Ceramic Society, vol. 24, issues 10-11, pp. 3155-3168.

[20] Murdoch, D.K., Day, C., Gierszewski, P., Penzhorn, R.D., Wu, C.H., 1999. "Tritium inventory issues for future reactors: choice parameters, limits, fusion", Engineering and design, vol. 46, issues 2-4, pp. 255-271.

[21] Muttamara S., Sales C.L. and Phunsiri S., 1996. "Solid waste recycling disposal and management in Bangkok", Journal of Solid Waste Technology and Management, vol. 23, No. 4. muse.wider.edu/ sxw0004/cumindex.html.

[22] Najm, M.A., El-Fadel, M., Ayoub, G., Taha, M. and Al-Awar, F., 2002. "An optimization model for regional integrated solid waste management II. Model application and sensitivity analysis", Waste Management and Research, vol. 20, No. 1, pp.46-54.

[23] Popoola, I.O., Oke, S.A., 2004, "Modelling solid waste recycling: A novel framework", Proceedings of CARS \& FOF 2004 San Cristobal - Tachira Venezuela.

[24] Stevenson, W. and White, J.R., 2002. "Photo-sensitivity of recycled photodegraded polystyrene", Journal of Material Science, vol. 37, No. 6, pp. 10911100 .

[25] Tofigh A.A., 2001. "Source separation and recycling in Tehran / Iran", Journal of Solid Waste Technology and Management, vol. 27, No. 2. muse.wider.edu/ sxw0004/cumindex.htm

[26] Treloar, G.J., Gupta, H., Love, P.E.D and Nguve, B., 2003. "An analysis of factors influencing waste minimization and use of recycled materials for the construction of residential building", Management of Environmental Quality: An International Journal, vol. 14, No. 1, pp. 134-145.

[27] Vaz, C.M., Van Doeveren, P.F., No. M., Reis, R.L., Cunha, A.M., 2003. "Development and design of double-layer co-injection moulded soy protein based drug delivery devices", Polymer, vol. 44, issue 19, pp. 5982-5992. 


\section{APPENDIX: Sensitivity analysis on the optimized model}

$$
\mathrm{Q}_{\mathrm{o}}=0.471 \mathrm{w}(\pi \mathrm{DN})^{\frac{3}{2}}\left(\frac{\mathrm{L} \mu_{a}}{\mathrm{P}}\right)^{\frac{1}{2}}(\operatorname{Cos} \theta)^{\frac{5}{2}}
$$

\section{Screw diameter, $\mathrm{D}$}

$$
\begin{aligned}
& \frac{\partial \mathrm{Q}_{\mathrm{o}}}{\partial \mathrm{D}}=0.471 \frac{3}{2}(\pi \mathrm{DN})^{\frac{3}{2}}\left(\frac{\mathrm{L} \mu_{a}}{\mathrm{P}}\right)^{\frac{1}{2}}(\operatorname{Cos} \theta)^{\frac{5}{2}} \mathrm{D}^{\frac{1}{2}} \\
& =0.707 \times 0.05 \times(\pi 1.67)^{\frac{3}{2}}\left(\frac{1.25 \times 1750}{50 \times 10^{6}}\right)^{\frac{1}{2}}\left(\operatorname{Cos} \frac{\pi}{4}\right)^{\frac{5}{2}} \mathrm{D}^{\frac{1}{2}}=1.181 \times 10^{-3} \mathrm{D}^{1 / 2}
\end{aligned}
$$

(i) Reducing by $50 \%(0.03 \mathrm{~m}) ; \frac{\partial \mathrm{Q}_{\mathrm{o}}}{\partial \mathrm{D}}=1.181 \times 10^{-3} \times(0.03)^{\frac{1}{2}}=2.046 \times 10^{-4}$

(ii) Increasing by $150 \%(0.15 \mathrm{~m}) ; \frac{\partial \mathrm{Q}_{\mathrm{o}}}{\partial \mathrm{D}}=1.181 \times 10^{-3} \times(0.15)^{\frac{1}{2}}=4.574 \times 10^{-4}$

\section{Channel width, w}

$$
\begin{aligned}
& \frac{\partial \mathrm{Q}_{\mathrm{o}}}{\partial \mathrm{w}}=0.471(\pi \mathrm{DN})^{\frac{3}{2}}\left(\frac{\mathrm{L} \mu_{a}}{\mathrm{P}}\right)^{\frac{1}{2}}(\operatorname{Cos} \theta)^{\frac{5}{2}} \\
& =0.471 \times(\pi \times 0.06 \times 1.67)^{\frac{3}{2}}\left(\frac{1.25 \times 1750}{50 \times 10^{6}}\right)^{\frac{1}{2}}\left(\operatorname{Cos} \frac{\pi}{4}\right)^{\frac{5}{2}}=2.313 \times 10^{-3}
\end{aligned}
$$

(i) Reducing by $50 \%(0.025 \mathrm{~m}) ; \frac{\partial \mathrm{Q}_{\mathrm{o}}}{\partial \mathrm{w}}=2.313 \times 10^{-4}$

(ii) Increasing by $150 \%(0.0125 \mathrm{~m}) ; \frac{\partial \mathrm{Q}_{\mathrm{o}}}{\partial \mathrm{w}}=2.313 \times 10^{-4}$

\section{Metering zone length, $L$}

$$
\begin{gathered}
\frac{\partial \mathrm{Q}_{\mathrm{o}}}{\partial \mathrm{L}}=0.471 \frac{1}{2} \times \mathrm{w}(\pi \mathrm{DN})^{\frac{3}{2}}\left(\frac{\mu_{a}}{\mathrm{P}}\right)^{\frac{1}{2}}(\operatorname{Cos} \theta)^{\frac{5}{2}} \mathrm{~L}^{-\frac{1}{2}} \\
=0.471 \times \frac{1}{2} \times 0.05 \times(\pi \times 0.06 \times 1.67)^{\frac{3}{2}}\left(\frac{1750}{50 \times 10^{6}}\right)^{\frac{1}{2}}\left(\operatorname{Cos} \frac{\pi}{4}\right)^{\frac{5}{2}} \mathrm{D}^{-\frac{1}{2}} \\
=5.173 \times 10^{-6} \mathrm{~L}^{-1 / 2}
\end{gathered}
$$


(i) Reducing by $50 \%(0.625 \mathrm{~m})$

$$
\frac{\partial \mathrm{Q}_{\mathrm{o}}}{\partial \mathrm{L}}=5.173 \times 10^{-6} \times(0.625)^{-\frac{1}{2}}=6.543 \times 10^{-6}
$$

(ii) Increasing by $150 \%(3.125 \mathrm{~m})$

$$
\frac{\partial \mathrm{Q}_{\mathrm{o}}}{\partial \mathrm{L}}=5.173 \times 10^{-6} \times(3.125)^{-\frac{1}{2}}=2.926 \times 10^{-6}
$$

\section{Screw speed, $N$}

$$
\begin{aligned}
& \frac{\partial \mathrm{Q}_{\mathrm{o}}}{\partial \mathrm{N}}=0.471 \frac{3}{2} \times 10(\pi \mathrm{D})^{\frac{3}{2}}\left(\frac{\mathrm{L} \mu_{a}}{\mathrm{P}}\right)^{\frac{1}{2}}(\operatorname{Cos} \theta)^{\frac{5}{2}} \mathrm{~N}^{\frac{1}{2}} \\
& =0.707 \times 0.05 \times(\pi \times 0.06)^{\frac{3}{2}}\left(\frac{1.25 \times 1750}{50 \times 10^{6}}\right)^{\frac{1}{2}}\left(\operatorname{Cos} \frac{\pi}{4}\right)^{\frac{5}{2}} \mathrm{~N}^{\frac{1}{2}}=8.045 \times 10^{-6} \mathrm{~N}^{1 / 2}
\end{aligned}
$$

(i) Reducing by $50 \%$ ( $0.835 \mathrm{rps})$

$$
\frac{\partial \mathrm{Q}_{\mathrm{o}}}{\partial \mathrm{D}}=1.181 \times 10^{-3} \times(0.03)^{\frac{1}{2}}=2.046 \times 10^{-4}
$$

(ii) Increasing by $150 \%(0.15 \mathrm{~m})$

$$
\frac{\partial \mathrm{Q}_{\mathrm{o}}}{\partial \mathrm{N}}=8.045 \times 10^{-6} \times(4.175)^{\frac{1}{2}}=1.644 \times 10^{-5}
$$

\section{Apparent viscosity, $\mu_{a}$}

$$
\begin{aligned}
& \frac{\partial \mathrm{Q}_{\mathrm{o}}}{\partial \mu_{a}}=0.471 \frac{1}{2} \mathrm{~W}(\pi \mathrm{DN})^{\frac{3}{2}}\left(\frac{\mathrm{L}}{\mathrm{P}}\right)^{\frac{1}{2}}(\operatorname{Cos} \theta)^{\frac{5}{2}} \mu_{a}^{-\frac{1}{2}} \\
& =0.471 \times \frac{1}{2} \times 0.05 \times(\pi \times 0.06 \times 1.67)^{\frac{3}{2}}\left(\frac{1.25}{50 \times 10^{6}}\right)^{\frac{1}{2}}\left(\operatorname{Cos} \frac{\pi}{4}\right)^{\frac{5}{2}} \mu_{a}^{-\frac{1}{2}} \\
& =1.383 \times 10^{-7} \mu_{a}^{-1 / 2}
\end{aligned}
$$

(i) Reducing by $50 \%(875 \mathrm{~Pa} . \mathrm{S})$

$$
\frac{\partial Q_{0}}{\partial \mu_{a}}=1.383 \times 10^{-7} \times(875)^{-\frac{1}{2}}=4.675 \times 10^{-9}
$$


(ii) Increasing by $150 \%(4375 \mathrm{~Pa} . \mathrm{S})$

$$
\frac{\partial \mathrm{Q}_{\mathrm{o}}}{\partial \mu_{a}}=1.383 \times 10^{-7} \times(437.5)^{-\frac{1}{2}}=2.091 \times 10^{-9}
$$

\section{Pressure, $\mathbf{P}$}

$$
\begin{aligned}
& \frac{\partial \mathrm{Q}_{\mathrm{o}}}{\partial \mathrm{P}}=-0.471 \times \frac{1}{2} \times \mathrm{wx}(\pi \mathrm{DN})^{\frac{3}{2}}\left(\mathrm{~L} \mu_{a}\right)^{\frac{1}{2}}(\operatorname{Cos} \theta)^{\frac{5}{2}} \mathrm{P}^{-\frac{3}{2}} \\
& =-0.471 \times \frac{1}{2} \times 0.05 \times(\pi \times 0.06 \times 1.67)^{\frac{3}{2}}(1.25 \times 1750)^{\frac{1}{2}}\left(\operatorname{Cos} \frac{\pi}{4}\right)^{\frac{5}{2}} \mathrm{P}^{-\frac{1}{2}} \\
& =4.09 \times 10^{-3} \mathrm{P}^{-3 / 2}
\end{aligned}
$$

(i) Reducing by $50 \%\left(25 \times 10^{6} \mathrm{~Pa}\right)$

$$
\frac{\partial \mathrm{Q}_{\mathrm{o}}}{\partial \mathrm{P}}=4.09 \times 10^{-3} \times\left(25 \times 10^{6}\right)^{-\frac{3}{2}}=3.272 \times 10^{-14}
$$

(ii) Increasing by $150 \%\left(125 \times 10^{6} \mathrm{~Pa}\right)$

$$
\frac{\partial \mathrm{Q}_{\mathrm{o}}}{\partial \mathrm{P}}=4.09 \times 10^{-3} \times\left(125 \times 10^{6}\right)^{-\frac{3}{2}}=2.927 \times 10^{-15}
$$

\section{Helix angle, $\theta$}

$$
\begin{aligned}
& \frac{\partial \mathrm{Q}_{\mathrm{o}}}{\partial \theta}=-0.471 \times \frac{5}{2} \times \mathrm{w}(\pi \mathrm{DN})^{\frac{3}{2}}\left(\mathrm{~L} \mu_{a}\right)^{\frac{1}{2}} \operatorname{Sin} \theta \operatorname{Cos}^{\frac{3}{2}} \theta \\
& =-0.471 \times \frac{5}{2} \times 0.05 \times(\pi \times 0.06 \times 1.67)^{\frac{3}{2}}\left(\frac{1.25 \times 1750}{50 \times 10^{6}}\right)^{\frac{1}{2}} \operatorname{Sin} \theta \operatorname{Cos}^{\frac{3}{2}} \theta \\
& =-6.878 \times 10^{-5} \mathrm{PS} \operatorname{Sin} \theta \operatorname{Cos}^{3 / 2} \theta
\end{aligned}
$$

(i) Reducing by $50 \%\left(\frac{\pi}{8}\right)$

$$
\frac{\partial \mathrm{Q}_{\mathrm{o}}}{\partial \theta}=-6.878 \times 10^{-5} \operatorname{Sin}\left(\frac{\pi}{8}\right) \operatorname{Cos}^{\frac{3}{2}}\left(\frac{\pi}{8}\right)=-2.337 \times 10^{-5}
$$


http://sajie.journals.ac.za

(ii) Increasing by $150 \%\left(\frac{5 \pi}{8}\right)$

$$
\frac{\partial \mathrm{Q}_{\mathrm{o}}}{\partial \theta}=-6.878 \times 10^{-5} \operatorname{Sin}\left(\frac{5 \pi}{8}\right) \operatorname{Cos}^{\frac{3}{2}}\left(\frac{5 \pi}{8}\right)=-1.504 \times 10^{-5}
$$

173 